\title{
Changes in Body Composition According to Age and Sex Among Young Non-Diabetic Korean Adults: the Kangbuk Samsung Health Study
}

\section{Jung Hwan Cho, Hyemi Kwon, Se Eun Park, Cheol-Young Park, Won-Young Lee, Ki-Won Oh, Sung-Woo Park, \\ Eun-Jung Rhee}

Division of Endocrinology and Metabolism, Department of Internal Medicine, Kangbuk Samsung Hospital, Sungkyunkwan University School of Medicine, Seoul, Korea

\section{Background}

-Weight loss is frequently observed in the elderly and is a unilaterally strong predictor of mortality. This phenomenon might reflect difficulties with homeostatic maintenance in older age. Elderly individuals experiencing weight loss would be expected to exhibit decreases in both the lean body mass and fat mass, and previous studies have shown that this decrease is more pronounced in lean body mass. Normally, the lean body mass peaks in the third to fourth decade of life, followed by a steady decline with further aging. In contrast, body weight increases until approximately 60 years of age, after which time $\geq 60 \%$ of the population will experience a decrease in weight. Therefore, fat mass accumulates during midlife. However, older people regulate weight less effectively than to younger people because the older people are less able to conserve lean mass during weight loss.

-According to several previous studies, sex might have affect the decrease in lean mass with aging Compared with men, women experience more complicated changes in body composition as they pass through menopause, including an abrupt decline in estrogen production. Because estrogen exerts multiple protective effects against metabolic disorders such as visceral obesity, osteoporosis, and atherosclerosis, women suffer from various metabolic diseases that lead to an increased risk of cardiovascular mortality after menopause.

-Studies have suggested sex- and age-related associations of weight changes with new-onset disabilities. Nevertheless, it remains controversial whether changes in body composition differ by age or sex.

\section{Aim of the study}

We aimed to analyze the changes of body weight and body composition during a 4-year follow-up study

\section{Methods}

-This is a retrospective single-center study conducted as part of the Kangbuk Samsung Health Study which included participants in a medical health checkup program at the Health Promotion Center of Kangbuk Samsung Hospital, Sungkyunkwan University, Seoul, Korea.

-The initial study population comprised 69,143 participants who participated in the medical checkup program between January and December 2010, as well as a repeated medical checkup between January and December 2014. Participants with diabetes in 2010 or missing values were excluded from the study. Finally, a total of 65,856 participants were enrolled in the initial study.

-The study protocol was approved by the institutional review board of Kangbuk Samsung Hospital. The requirement for informed consent was waived because the study used non-identified data that were routinely collected during the health screening process.

-The participants' body compositions were measured using segmental bioelectric impedance analysis (BIA) with eight tactile electrodes according to the manufacturer's instructions (InBody 3.0, Biospace, Korea). The lean mass $(\mathrm{kg})$, fat mass $(\mathrm{kg})$, percent fat mass $(\%)$, and waist-hip ratio were measured. BIA is a useful and well-correlated measurement of body fat relative to lean mass

\section{Results}

Table 1. General characteristics of the participants at baseline and after 4 years

$\frac{\text { Variables }}{\text { Age (yrs) }}$

Sex, male $(\%)$

Fasting blood glucose $(\mathrm{mg} / \mathrm{dL})$

Aspartate aminotransferase (IU/L)

Alanine aminotransferase (IU/L)

Total cholesterol (mg/dL)

Triglyceride $(\mathrm{mg} / \mathrm{dL})$

High-density lipoprotein cholesterol $(\mathrm{mg} / \mathrm{dL})$

Low-density lipoprotein cholesterol $(\mathrm{mg} / \mathrm{dL})$

Glycated hemoglobin (HbA1c) (\%)

Systolic blood pressure (mmHg)

Diastolic blood pressure $(\mathrm{mmHg})$

Body weight $(\mathrm{kg})$

Body mass index $\left(\mathrm{kg} / \mathrm{m}^{2}\right)$

Muscle mass (kg)

Body fat mass (kg)

Body weight change $(\mathrm{kg})$

Percent change of body weight (\%)

Lean mass change $(\mathrm{kg})$

Percent change of lean mass (\%)

Annual percent change of lean mass (\%)

Fat mass change $(\mathrm{kg})$

Percent change of fat mass (\%)

Annual percent change of fat mass (\%)

Regular exercise (\%)

Alcohol consumption (\%)

Table 2. Baseline values and changes in metabolic parameters during the 4-year follow-up period

$\underline{\text { pe }}$

Age (y

Sex, male (\%)

Body weight $(\mathrm{kg})$

Body mass index $\left(\mathrm{kg} / \mathrm{m}^{2}\right)$

Muscle mass (kg)

Body fat mass $(\mathrm{kg})$

Body weight change $(\mathrm{kg})$

Percent change of body

weight $(\%)$

Lean mass change $(\mathrm{kg})$

Percent change of lean mass

$(\%)$

Annual percent change of

lean mass $(\mathrm{kg})$

Fat mass change $(\mathrm{kg})$

Perce

$(\%)$

Annual percent change of

fat mass $(\mathrm{kg})$
Table 3. Comparison of mean metabolic parameter values among the groups divided by age and weight change

\begin{tabular}{|c|c|c|c|c|c|c|c|}
\hline & $\begin{array}{c}\text { Age }<50 \text { yrs } \\
\text { and weight } \\
\text { change }<- \\
5 \% \\
(\mathrm{~N}=6,923)\end{array}$ & $\begin{array}{c}\text { Age } \geq 50 \text { yrs } \\
\text { and weight } \\
\text { change }<- \\
5 \%(\mathrm{~N}= \\
441)\end{array}$ & $\begin{array}{c}\text { Age }<50 \text { yrs } \\
\text { and weight } \\
\text { change -5- } \\
5 \%(\mathrm{~N}= \\
44,599)\end{array}$ & $\begin{array}{c}\text { Age } \geq 50 \text { yrs } \\
\text { and weight } \\
\text { change }-5- \\
5 \%)(\mathrm{N}= \\
2,984)\end{array}$ & $\begin{array}{c}\text { Age }<50 \\
\text { yrs and } \\
\text { weight } \\
\text { change } \\
>5 \%(\mathrm{~N}= \\
10,610) \\
\end{array}$ & $\begin{array}{c}\text { Age } \geq 50 \\
\text { yrs and } \\
\text { weight } \\
\text { change } \\
>5 \%(\mathrm{~N}= \\
299)\end{array}$ & $\begin{array}{c}\mathrm{P} \\
\text { value }\end{array}$ \\
\hline$\overline{\text { Age (yrs) }}$ & $38.2 \pm 5.4$ & $55.1 \pm 5.9$ & $38.6 \pm 5.3$ & $54.4 \pm 5.3$ & $36.7 \pm 5.3$ & $54.2 \pm 5.1$ & $<0.01$ \\
\hline Se & 52.5) & $297(67.3)$ & $27149(60.9)$ & $1978(66.3)$ & $5920(55.8)$ & $178(59.5)$ & $<0.01$ \\
\hline Body weight $(k$ & $68.2 \pm 12.8$ & $66.5 \pm 10.5$ & $66.3 \pm 12.3$ & $65.5 \pm 9.9$ & $64.1 \pm 11.8$ & $62.7 \pm 10.1$ & $<0.01$ \\
\hline $\mathrm{x}\left(\mathrm{kg} / \mathrm{m}^{2}\right)$ & $26.3 \pm 3.2$ & $24.3 \pm 2.7$ & & $23.8 \pm 2.6$ & $22.6 \pm 3.1$ & $22.9 \pm 2.7$ & $<0.01$ \\
\hline Musc & $46.8 \pm$ & & & & $45.9 \pm 9.1$ & $44.3 \pm 8.1$ & $<0.01$ \\
\hline Body & $18.5 \pm 5.6$ & $17.2 \pm 4.8$ & 16.3 & $16.5 \pm 4.8$ & $15.4 \pm 5.5$ & $15.7 \pm 5.0$ & $<0.01$ \\
\hline Body & $=1$ & -4.83 & 0.15 & $-0.18 \pm 1.6$ & $5.32 \pm 2.4$ & $4.73 \pm 1.7$ & $<0.01$ \\
\hline $\begin{array}{l}\text { Percent change of body } \\
\text { weight }(\%)\end{array}$ & $-8.10 \pm$ & $-7.25 \pm 2.3$ & $0.25 \pm 2.6$ & $-0.26 \pm 2.5$ & $8.34 \pm 3.5$ & $7.61 \pm 2.7$ & $<0.01$ \\
\hline Lean mass change $(\mathrm{kg})$ & & & & & $0.83 \pm 1.6$ & $0.60 \pm 1.5$ & $<0.01$ \\
\hline $\begin{array}{l}\text { Percent change of lean } \\
\text { mass (\%) }\end{array}$ & -2 & -3. & -0 & & $1.25 \pm 2.5$ & $0.89 \pm 2.4$ & $<0.01$ \\
\hline $\begin{array}{l}\text { Annual percent change of } \\
\text { lean mass }(\%)\end{array}$ & $-0.70 \pm 0.6$ & $-0.82 \pm 0.6$ & $-0.22 \pm 0.6$ & $-0.34 \pm 0.6$ & $0.31 \pm 0.6$ & $0.22 \pm 0.6$ & $<0.01$ \\
\hline Fat ma & & & & & $4.44 \pm 2.3$ & $4.13 \pm 2.0$ & $<0.01$ \\
\hline $\begin{array}{l}\text { Percent change of fat mass } \\
(\%)\end{array}$ & -5.06 & $-3.62 \pm 3.1$ & 2.9 & .9 & $7.00 \pm 3.6$ & $6.74 \pm 3.4$ & $<0.01$ \\
\hline $\begin{array}{l}\text { Annual percent change of } \\
\text { fat mass }(\%)\end{array}$ & $-1.27 \pm 0.9$ & $-0.90 \pm 0.8$ & $0.30 \pm 0.7$ & $0.33 \pm 0.7$ & $1.75 \pm 0.9$ & $1.69 \pm 0.9$ & $<0.01$ \\
\hline Regu & & & & & $716(25.6)$ & 1) & 0.01 \\
\hline & & & $9,940(22.3)$ & & $2,627(24.8)$ & & \\
\hline Alcohol consumption (\%) & $1,101(15.9)$ & $92(20.9)$ & $7,552(16.9)$ & 678 (22.7) & 1,441 (13.6) & $66(22.1)$ & $<0.01$ \\
\hline
\end{tabular}

Table 4. Odds ratios for a rapid annual decrease in lean mass (lowest quartile*)

\begin{tabular}{lccccc}
\hline & $\begin{array}{c}\text { Numbers of } \\
\text { subjects }(\%)\end{array}$ & Model 1 & Model 2 & Model 3 & Model 4 \\
\hline $30 \mathrm{~s}$ & $\begin{array}{c}\text { 8,361/53,829 } \\
(23.3)\end{array}$ & 1.000 & 1.000 & 1.000 & 1.000 \\
& & & & \\
$40 \mathrm{~s}$ & $6,810 / 26,303$ & 1.148 & 1.148 & 1.205 & 1.200 \\
& $(25.9)$ & $(1.106-1.191)$ & $(1.106-1.191)$ & $(1.143-1.271)$ & $(1.134-1.270)$ \\
$50 \mathrm{~s}$ & $1,038 / 3,135(33.1)$ & 1.626 & 1.627 & 1.576 & 1.573 \\
& & $(1.504-1.759)$ & $(1.504-1.760)$ & $(1.436-1.730)$ & $(1.422-1.741)$ \\
& & 2.002 & 2.000 & 1.921 & 2.081 \\
& $223 / 589(37.9)$ & $(1.692-2.369)$ & $(1.690-2.367)$ & $(1.585-2.328)$ & $(1.678-2.581)$ \\
\hline
\end{tabular}

Fig. 1. Comparison of the mean percent change of body weight, lean mass, and fat mass among three groups divided by the percent weight change over 4 years and age at baseline

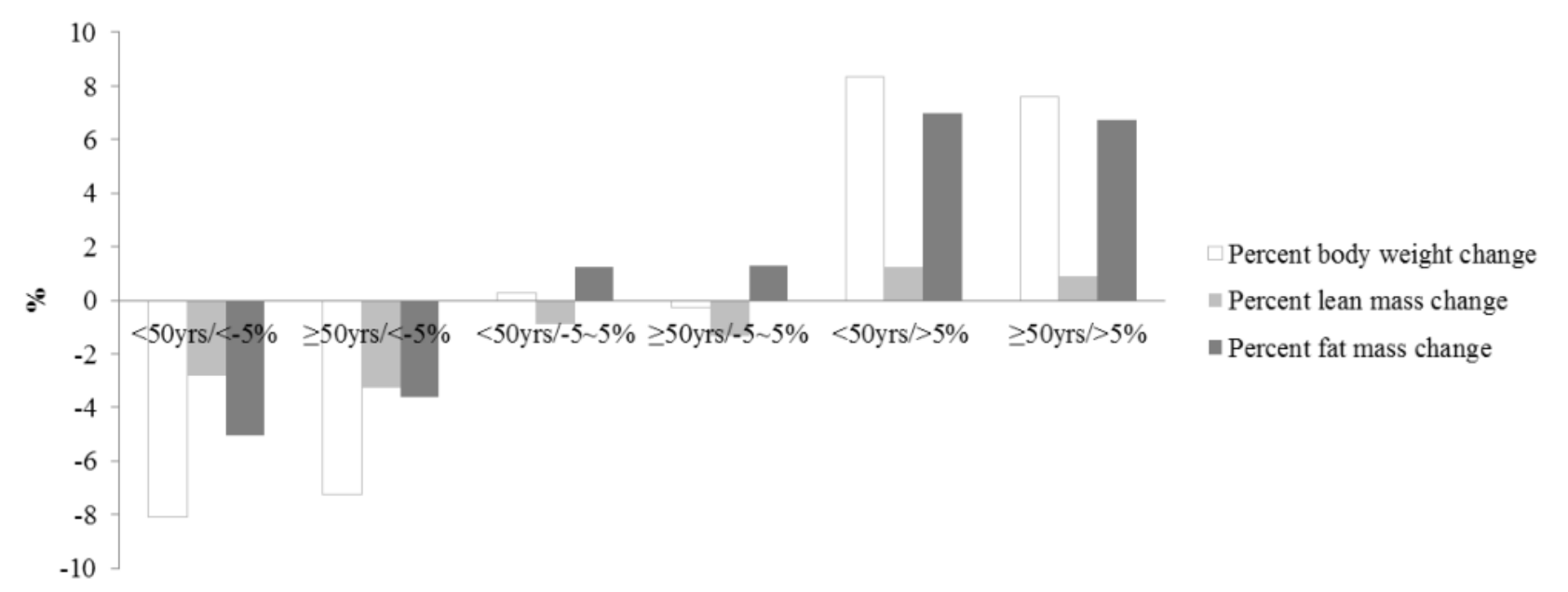

Fig. 2. Comparison of percent changes in lean and fat mass during a 4-year period by age and sex

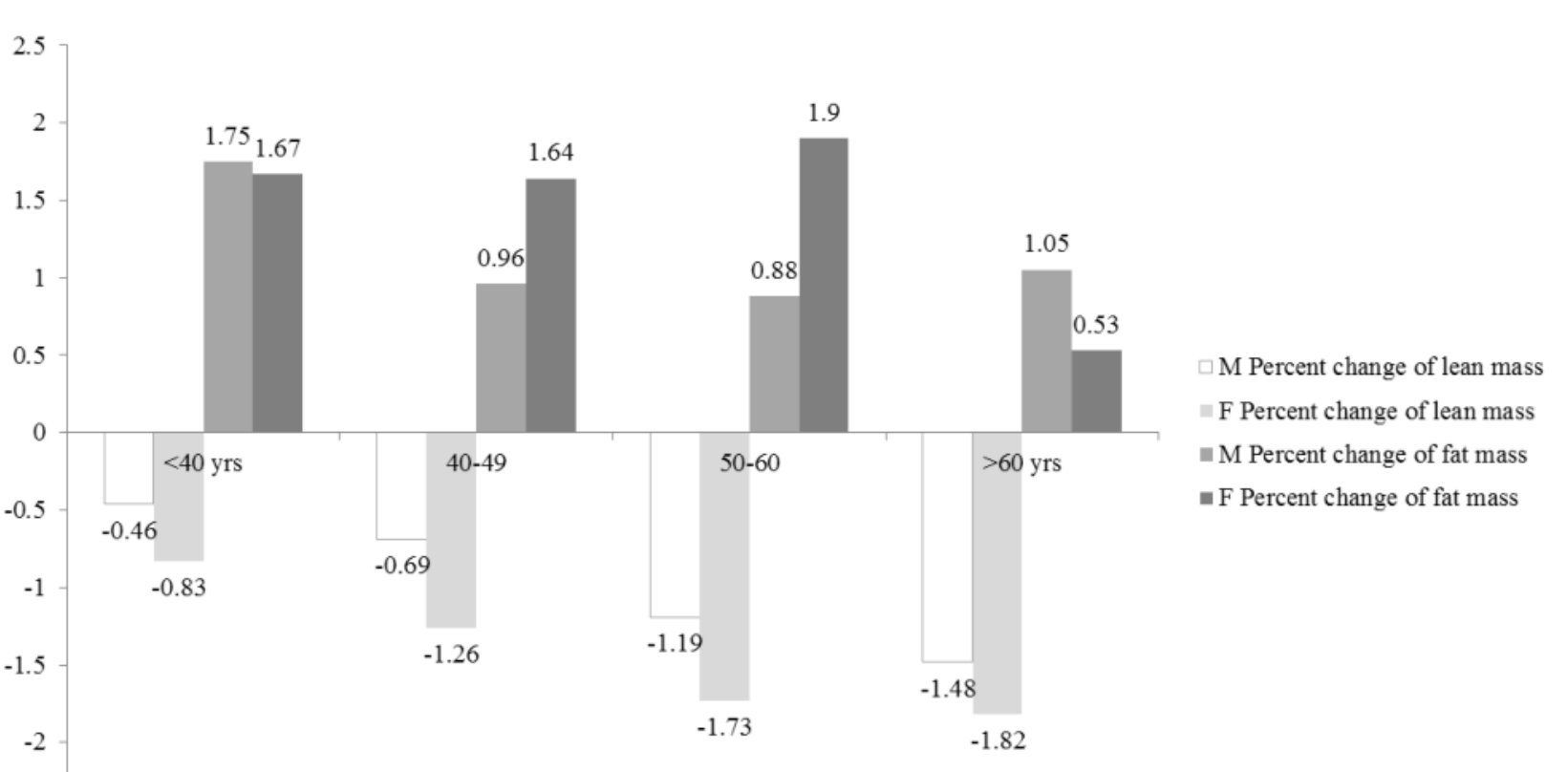

\section{Conclusion}

- We observed body weight changes and body composition changes during a large 4-year follow-up study of non-diabetic Korean young adults, and found that the lean mass significantly decreased with increasing age, even among relatively young adults.

- Women had a greater risk of a rapid decrease in lean mass, relative to men. This difference in body composition during the 4-year study might be attributable to aging processes and sex-related genetic differences, as well as racial differences.

- A larger population that includes multiple races and is conducted over a longer period of time is needed to understand the mechanism underlying the observed changes in body composition patterns, thus facilitating the application of these findings to the management of elderly and social health. 